\title{
HERMENEUTICS AND CONSTITUTIONAL INTERPRETATION
}

\author{
Aharon Barak *
}

\section{The Problem}

I am a judge. For me, a constitution is an operational document. I decide cases by extracting meaning from its text. The process of extracting meaning from the text of the constitution, as with any document, is the process of interpretation, and so the question presented to me is: How do you interpret a constitution? It is not an answer to say "Words have no meaning; do whatever you think politically expedient." Words do have meaning. A cigarette is not an elephant. I am a judge, not a politician. I do not have a political agenda; I do not represent a constituency. It is not my role, nor do I desire, to impose my subjective will on the polity. I am required to act judiciously, objectively, consistently, coherently. It is no answer to me to advise, "Think and act prudently, pragmatically, reasonably." What does "prudently" mean? When am I acting "pragmatically"?

It is also no answer to say "Read the text and apply it." To read and apply requires the intermediate step: to construe. The words of a constitution, like the words of any other document, may have several meanings. What meaning should I choose? Words can be applied on different levels of generality and abstraction. Which level should I choose?

It may be said "Choose the level of generality and abstraction that fits the intent of the framers of the constitution." But why should I? Is the purpose of interpretation to further their intent? Isn't the purpose of interpretation to further the purpose of the constitution?

In order to know how to read a constitution I must have a better understanding of interpretation. What is "interpretation" and how is it accomplished? I realize soon, that I am faced with similar questions when I read other texts. How does one read a contract, a statute, a will? Do I read a constitution the same way I read a will? Do we not always have to be aware that "it is a constitution we are ex-

* Ph.D., Hebrew University, 1963; Professor, Hebrew University, 1960-74; Dean, Hebrew University, 1974-75; Justice, Supreme Court of Israel, 1978-present; Legal Advisor to the Israeli Delegation of Peace Negotiations with Egypt, including Camp David. 
pounding"? All these documents must be interpreted, but is there a uniform theory for reading them all?

Perhaps the suggestion that I read a constitution in a way that implements the intent of the founding fathers provides the answer. Isn't this the case with wills-one should, perhaps, interpret a will in a manner that implements the intent of the deceased. But then I recall that a contract should be interpreted "objectively," and that the intent of one party should not matter so long as it is not shared by the other party; there are reliance interests to be taken into account. Aren't there reliance interests to be accounted for when one interprets the constitution or a statute?

By now it is clear to me: I need a theory of interpretation. Not a meta-theory-a theory about theories - but a workable theory of how to read a legal text generally and a constitutional text in particular.

Judges, scholars, lawyers, and the public interpret legal texts every day. Most of them reach the same results most of the time. There is law outside the courts. Not every case is a hard case; there are easy cases. Not every case reaches the Supreme Court. There must be a common method-accepted by the legal community-to interpret a legal text.

\section{THE TeXT}

I start with the text-whether it is a will, a contract, a statute, or a constitution. Interpretation requires that I give it meaning. In adjudicating, the meaning I must give is the "legal" meaning, that is, the normative meaning. My first general rule of interpretation is: one should not give to the text a legal meaning that is not supported by its literal meaning. The literal meaning, or rather the zone of literal meanings, marks the boundary between interpreting an existing text and creating a new one. We must distinguish between text and meaning. As interpreters we can change our understanding of the meaning of the text, but we can't change the text. Legal interpretation is a process of choice of meaning that must be confined to the zone of literal meaning.

The normative force of interpretation derives from the normative force of the text itself. The court's interpretation is not at a normative level above the text or below the text; it is a choice, among different literal meanings of the text. The court's constitutional interpretation is not the supreme law of the land. The court's constitutional interpretation is the legally binding choice of what the Constitution, as supreme law of the land, means. 


\section{The Choice}

If legal interpretation is a choice within the zone of possible literal meanings of the text, how is this choice to be made? Is there a choice that is "true to the meaning of the text?" Is there a right or wrong choice? My answer is simple: There is no "true" interpretation. There is no "true" meaning. There is only "proper" interpretation. There are different methods or theories for choosing the legally binding meaning of the text, and a choice must be made among these theories. But none of the theories has a claim to truth.

The choice among different methods for extracting legal from literal meaning is not itself an interpretative choice; it is not conducted by rules of interpretation. If the study of hermeneutics teaches anything, it teaches us that hermeneutics cannot tell us which hermeneutical approach to use. The choice among the different methods or theories is a policy choice. Every theory of interpretation is the outcome of noninterpretive considerations. The choice is not the individual exercise of a judge or scholar; it is a choice made by generations of judges and scholars throughout history. These choices determine the nature of the interpretive legal community.

There are legal communities, however, in which there is no consensus on how the choice should be made. The American legal community is one example; it is divided mainly because of the problem of judicial review. The Israeli legal community is another; the failure of consensus can be traced mainly to the problems posed by the transfer from British rule to independence. What, then, can I suggest about the proper choice among thoeries of interpretation in the context of such a divided legal community?

\section{A. Purposive Interpretation}

My starting point is the purpose of the law. For me, every law has a purpose. These purposes include, among others, the ethical, social, and economic, objectives that law as a social institution must fulfill. If law has a purpose, and if any specific legal norm has its purpose, then interpretation has to be a tool for effectuating the law's purpose. My theory of interpretation of the legal text recommends the choice within the range of possible literal meanings, of that particular meaning which, more than any other, furthers the purpose of the norm embodied in the text. If one wishes, one can call it "purposive interpretation." Thus, just as the aim of interpreting a will or a contract is to further its purpose, the aim of interpreting a statute or a constitution is to further its purpose. This theory furthers the democratic notions of representative government, separation of powers, 
and the rule of law. Since it furthers the basic values of the society, it furthers human rights and other values that it is the law's function to fulfill.

Thus, the object of interpretation of a given legal text is to make a choice, within the literal zone, that furthers the purpose of the norm embodied in the text, not the intent of the creator of the text. The purpose of a norm is not a psychological concept. It is a normative concept. It is not something to be "found" or "discovered" in the text. It is a legal concept, an abstraction, a construction, to be created outside the text. In creating this abstraction, the interpreter is not wholly free; but he is not fully bound, either. How then is the purpose established?

\section{B. Establishment of Purpose}

Among the sources from which the purpose of a legal norm is to be extracted is, first and foremost, the intent of those who created the text. Intent is a tool for understanding purpose. We may call it the "subjective purpose." The relevant intent is the intent concerning the purpose of the norm-it is the general purpose. Usually there will be several purposes with different levels of abstraction. The relevant intent is not aimed at knowing how the creator of the text would solve the problem faced by the interpreter. We do not ask counter factual questions. The relevant intent is aimed at the creator's concept of the general and abstract purpose of the legal norm that was created.

The purpose of the legal norm is not exclusively a "subjective purpose." The legal norm also has "objective purposes." These objective purposes are the ones that the legal community wants to achieve with its norms, and they represent the deep and basic understandings of the legal community. They consist of the values and policies that establish the identity of the community. Their origin is in the past. They were developed by generations of judges and precedents. They are the outcome of history and tradition. They reflect the legal community's understanding of its identity and its diversity.

The subjective purpose and the objective purpose usually coincide. It is usually the subjective purpose of the text's creator to further the objective purposes of the community. But the two kinds of purposes have to be distinguished. The creators of the text may not have had in their mind any of the objective purposes. They may even have had a subjective purpose which is at odds with some objective purpose. What are, then, the interrelationships between these purposes?

There is no "true" answer to that question. It is a policy deci- 
sion, to be accepted or rejected by the legal community. It cannot be the same answer for all legal texts. You may say, for example, that with regard to wills, the subjective purpose always prevails unless it is illegal. The objective purpose only supplements. You may also claim that as to contracts, the common subjective purpose of the parties prevails, while the objective purpose applies to third parties who have no knowledge of the subjective purpose. Beyond that, absent information on subjective purpose, one may refer to objective purpose.

Where statutes are in question, it seems to me that a subjective purpose embodied in the express words of the statute should prevail over objective purpose. This fits our understanding of the functions of legislators and judges, as well as our notions concerning the separation of power. If the legislature does not like the outcome, the statue can be changed. Still, the objective purpose plays a critical role. It is the criterion by which a choice is made among conflicting subjective purposes; it creates a strong presumption about purpose, and only reliable and convincing evidence of subjective purpose can overcome this presumption. Furthermore, if there are fundamental changes in the outlook of the legal community, including changes brought about by subsequent statutes, the subjective purpose may be found entirely unacceptable. If the subjective purpose conflicts with the objective purpose, and the objective purpose is embodied in the constitutional text, the subjective purpose can result in a declaration that the statute is unconstitutional.

This brings me to the interrelationship between subjective and objective purpose in constitutional interpretation. But before moving on to that subject, it is helpful to make some observations concerning judicial discretion in interpretation.

\section{Judicial Discretion}

"Judicial discretion" is the power of the judge to choose among several interpretative alternatives, each of which is lawful. This definition assumes, of course, that the judge will not act mechanically, but instead will weigh, reflect, test, and study. Yet, this conscious use of the power of thought does not define judicial discretion. Judicial discretion, by definition, is neither an emotional nor a mental state. It is, rather, a normative condition, in which the judge has the freedom to choose among a number of interpretive options.

Any theory of interpretation must assume the existence of judicial discretion. There can be no interpretation without discretion. Interpretive theories differ as to the scope of discretion, but not as to its existence. Subjective theories of interpretation assume discretion, at 
least as to the level of generality among different subjective purposes. Objective theories of interpretation assume discretion, as to the different levels of objective purposes, and as to the weighing and balancing among conflicting values or principles. Thus, it would be a grave mistake to formulate any theory of interpretation without integrating, as an integral part, a theory of discretion. In fact, the recommendations for the use of judicial discretion form the most important aspects of any interpretive theory. Thus, the choice between subjective and objective purposes in interpretation has to be integrated into a broader concept of judicial discretion. Such integration is especially necessary when the subject is constitutional interpretation, as the basic considerations regarding judicial discretion are constitutional in nature. These considerations raise questions about the role of a judge in a democratic society. The questions are intimately associated with the constitutional role of the judge as interpreter of the constitutional text.

\section{Purposive Constitutional Interpretation}

What is the proper mix of subjective and objective purposes in constitutional interpretation? This too, of course, is a policy decision to be made by the general consensus of the legal community. Absent such consensus, what is the "proper" way to make this choice? Is it the same choice in statutory interpretation as in constitutional interpretation?

The full answer to this question requires more time than I have today, as it raises many fundamental issues. I can only provide a short answer: constitutional interpretation is different from statutory, as well as other legal interpretation. The difference lies in the special character of the constitutional text.

The purpose of the constitutional text is to provide a solid foundation for national existence. It is to embody the basic aspirations of the people. It is to guide future generations by its basic choices. It is to control majorities and protect individual dignity and liberty. All these purposes cannot be fulfilled if the only guide to interpretation is the subjective purposes of the framers of the constitutional text. The constitution will not achieve its purposes if its vision is restricted to the horizons of its founding fathers. Even if we assume the broadest generalizations of subjective purpose, this may not suffice. It may not provide a solid foundation for modern national existence. It may be foreign to the basic aspirations of modern people. It may not be consistent with the dignity and liberty of the modern human being. A constitution must be wiser than its creators.

It is my view, therefore, that in constitutional interpretation, un- 
like in other legal interpretation, the objective purpose should prevail. However, in the realization of the objective purpose as a normative concept, the past should not be forgotten. The objective purpose is a vision of life, embodied within the zone of literal meaning, that has its origin in the past. It is a reflection of higher values transferred from one generation to another, a fulfillment of basic values embodied in past decisions. It is a carry-over of old traditions into the modern environment. It is the modern understanding shaped by past experiences of the role of the individual in the state.

Of course, such an interpretation restricts the current majority, acting via an ordinary statute. In this respect, a judge exercising this kind of interpretation is acting in a counter-majoritarian fashion. But, so is a judge who interprets the constitutional text according to the subjective purpose of the creator of the text. The legitimacy of any theory of interpretation does not come from the text or from the creator's intent. The legitimacy of every theory of constitutional interpretation-like the legitimacy of the constitution itself-derives from non-legal sources outside the subjective purpose method of interpretation and may also legitimize the objective purpose method of interpretation.

In establishing the purpose of the constitutional norm, the judge has discretion, but not unlimited discretion. It is a discretion rooted in history and tradition. The vision of the judge concerning modern purposes must be compatible with his vision of the historic purposes. The modern purpose must conform to the level of generality already recognized by other judges in modern times. Precedent must generally be respected. A judge should not impose personal values; instead, he should try to reflect the basic values of national life. These values do not represent majority views or minority views; they reflect basic ideals. They should fit comfortably into the coherent and natural development of basic concepts. They should fit the constitutional structure and system, and be continuous with the constitutional scheme. A constitution is not a collection of articles; it is a unified whole to be applied with a broad view. A constitution is an integrated document in which the interpretation of one of the articles requires the interpretation of the whole text.

But there is discretion. In exercising his discretion, a judge is asked to be a historian, a philosopher, and a prophet. The judge may fail. Though his decisions may be final, they are not infallible, and the judge may commit grave mistakes. He may misread the national way of life. He may not strike the proper balance between stability and change. He may further his subjective views, and not the heritage of 
the system. He may be influenced by temporary, fleeting trends and ideas. Those are the risks that must be taken into account. No theory of interpretation can prevent mistakes. The question is, does my theory of interpretation generally, and my theory of constitutional interpretation in particular, fulfill its purpose? Does the judge as a constitutional interpreter fulfill a proper function in the general constitutional scheme? Does he stand the constitutional trial? I hope the answer is positive, though I realize the challenges this answer faces. As a judge, I should know my limitations. As our elders said, "You would think that I am granting you power? It is slavery that I am imposing on you." 